\title{
Proteomic data show an increase in autoantibodies and alpha-fetoprotein and a decrease in apolipoprotein A-II with time in sera from senescence-accelerated mice
}

\author{
S.J. Guo ${ }^{1,3}$, C.H. Qi ${ }^{1}$, W.X. Zhou ${ }^{1}$, Y.X. Zhang ${ }^{1}$, X.M. Zhang ${ }^{2}$, J. Wang ${ }^{2}$ and H.X. Wang ${ }^{2}$ \\ ${ }^{1}$ Beijing Institute of Pharmacology and Toxicology, Beijing, China \\ ${ }^{2}$ National Center of Biomedical Analysis, Beijing, China \\ ${ }^{3}$ Shanghai Key Laboratory of Hypertension, Ruijin Hospital, Shanghai Jiaotong University School of Medicine, Shanghai, China
}

\begin{abstract}
We evaluated changes in levels by comparing serum proteins in senescence-accelerated mouse-prone 8 (SAMP8) mice at 2 , 6,12 , and 15 month of age (SAMP8-2 m, $-6 \mathrm{~m},-12 \mathrm{~m},-15 \mathrm{~m}$ ) to age-matched SAM-resistant 1 (SAMR1) mice. Mice were sacrificed, and blood was analyzed by 2-dimensional electrophoresis combined with mass spectrometry. Five protein spots were present in all SAMP8 serum samples, but only appeared in SAMR1 samples at 15 months of age except for spot 3, which also showed a slight expression in SAMR1-12 m sera. Two proteins decreased in the sera from SAMP8-2 m, -6 m, and -12 m mice, and divided into 2 spots each in SAMP8-15 m sera. Thus, the total number of altered spots in SAMP8 sera was 7; of these, 4 were identified as Ig kappa chain $\mathrm{V}$ region (M-T413), chain $\mathrm{A}$ of an activity suppressing Fab fragment to cytochrome P450 aromatase (32C2_A), alpha-fetoprotein, and apolipoprotein A-II. M-T413 is a monoclonal CD4 antibody, which inhibits T cell proliferation. We found that M-T413 RNA level was significantly enhanced in splenocytes from SAMP8-2 m mice. This agreed with serum M-T413 protein alterations and a strikingly lower blood CD4 ${ }^{+}$T cell count in SAMP8 mice when compared to the age-matched SAMR1 mice, with the latter negatively correlating with serum M-T413 protein volume. Age-related changes in serum proteins favored an increase in autoantibodies and alpha-fetoprotein and a decrease of apolipoprotein A-II, which occurred in SAMP8 mice at 2 months of age and onwards. These proteins may serve as candidate biomarkers for early aging.
\end{abstract}

Key words: SAMP8; Serum proteins; 2-DE; Mass spectrometry; M-T413

\section{Introduction}

Alzheimer's disease (AD), as the prevalent form of progressive dementia, is representative of diseases related to impaired cognition: its early diagnosis so far remains challenging, although some symptomatic treatments and new drugs are emerging to delay and/or reverse its progress (1). It is therefore essential to identify the mechanisms of poor cognition by using biomarkers to facilitate the early diagnosis of neurodegenerative diseases characterized by deficits in learning and memory.

Mounting evidence has indicated that impaired cognition was slight but significant as early as at 2 months of age, and became more obvious with aging in senescenceaccelerated mouse-prone 8 (SAMP8) mice compared to SAM-resistant 1 (SAMR1) mice, which exhibit normal aging processes $(2,3)$. Moreover, SAMP8 mice also exhibited many of the biochemical findings of $A D$, such as decreased glucose metabolism and alterations in amyloid precursor protein, apolipoprotein E, bcl-2, presenilin-2, tau, and some oxidative markers (4-6). Taken together, these studies demonstrate that the SAMP8 mouse might be an ideal animal model for the investigation of the mechanisms underlying age-related learning and memory deficits in AD within the framework of gene and protein levels (7). Accordingly, a series of advanced genomic and proteomic investigations have been conducted in the brain, liver, and spleen tissue of SAMP8 mice and have shown that signal transduction change, impaired neuroprotection, abnormal fatty acid metabolism, depressed energy production, and enhanced oxidative stress-induced molecular damage were reportedly involved in learning and memory deficits (8-15). However, considering clinical practicability, it is undoubtedly optimal 
to identify the biomarkers contributing to these deficits in serum. The SAMP8 mouse has been employed since 1986 to assess age-related neurobiological features and to understand their pathological mechanisms. However, data on serum changes in accelerated senescence mice are relatively limited. For example, SAMP8 mice displayed an age-related decrease in testosterone and estradiol $(16,17)$. In addition, dozens of abnormal metabolites were found in SAMP8 mouse sera. Among these, the most important metabolite responsible for the strain separation was a lack of inosine, which meant that the protective functions of anti-inflammation, immunomodulation and neuroprotection might be attenuated in SAMP8 mice (18). In addition, regarding serum proteins, decreased immunoglobulin E ( $\lg E)$ (19) and increased anti-elastin antibodies (20) occurred in SAMP8 mouse serum, with the latter supporting a relationship between autoantibody and aging in SAMP8 mice for the very first time. To identify more age-relevant proteins, systematic views on serum protein changes during the aging process are warranted.

In the present study, we combined 2-dimensional electrophoresis (2-DE) with robust mass-spectrometrybased proteomic approaches to compare differential expression patterns of serum proteins between SAMP8 and SAMR1 mice at 2, 6, 12, and 15 months of age. This is the first time that the pathophysiological development of the SAMP8 mouse serum proteome has been investigated by evaluating global changes that occur with aging. Our results provide some information for understanding the dysfunction in the senescence-accelerated mouse and identifying potential novel serum biomarkers for early aging.

\section{Material and Methods}

\section{Ethics statement}

Male SAMP8 mice at 2, 6, 12, and 15 months of age (SAMP8-2 m, -6 m, -12 m, -15 m) and age-matched SAMR1 mice were generously provided by $\mathrm{Dr}$. Toshio Takeda, Kyoto University, and maintained at the Laboratory Animal Center of the Academy of Military Medical Sciences (Protocol: SYXK JUN 2007-004). The mice were treated according to the Guide for the Care and Use of Laboratory Animals of the National Institutes of Health with the approval (Protocol: SYXK JUN 2007-008) of the Animal Care and Use Committee of the National Beijing Center for Drug Safety Evaluation and Research.

\section{2-DE and analysis}

Mice $(n=4-5)$ were sacrificed after collection of blood samples $(0.5 \mathrm{~mL} /$ mouse) by removing the eyeball. The blood was allowed to clot for $30 \mathrm{~min}$ at room temperature. Sera were obtained by centrifugation at $112 \mathrm{~g}$ for $10 \mathrm{~min}$ at $4^{\circ} \mathrm{C}$ and preserved at $-80^{\circ} \mathrm{C}$ until use.

Each serum sample was separated by 2-DE. After determining protein concentration by the Bradford assay using bovine serum albumin as standard, $150 \mu \mathrm{g}$ protein (for the comparative analysis of protein spots) or $1.5 \mathrm{mg}$ protein from the serum of 1 mouse (for protein identification by mass spectrometry) was diluted with a rehydration buffer [8 M urea; 2\% (w/v) CHAPS; 20 mM DTT; 0.5\% (v/ v) Immobilized $\mathrm{pH}$ Gradient (IPG) buffer, $\mathrm{pH} 3-10$, and $0.002 \%$ bromophenol blue] to $350 \mu \mathrm{L}$ and was then applied to IPG strips $(18 \mathrm{~cm}, \mathrm{pH} 3-10$ linear, GE Healthcare Bioscience, Sweden). Isoelectric focusing was performed with the IPGphor system (GE Healthcare Bioscience) according to the following programmed settings: $30 \mathrm{~V}$ for $6 \mathrm{~h}, 60 \mathrm{~V}$ for $6 \mathrm{~h}, 200 \mathrm{~V}$ for $1 \mathrm{~h}, 500 \mathrm{~V}$ for $1 \mathrm{~h}, 1000 \mathrm{~V}$ for $1 \mathrm{~h}$, and $8000 \mathrm{~V}$ for $1 \mathrm{~h}$ at gradient type, and $8000 \mathrm{~V}$ until reaching $64 \mathrm{kVh}$. Accordingly, the IPG strip was equilibrated for $15 \mathrm{~min}$ in an equilibration buffer containing $6 \mathrm{M}$ urea, $50 \mathrm{mM}$ Tris- $\mathrm{HCl}, 30 \%$ (v/v) glycerol, $2 \%(w / v)$ SDS and $0.02 \%(w / v)$ bromophenol blue with $10 \mathrm{~g} / \mathrm{L}$ DTT, and then equilibrated for another $15 \mathrm{~min}$ in the same buffer but with $25 \mathrm{~g} / \mathrm{L}$ iodoacetamide replacing the DTT. The second dimension electrophoresis was performed on $12.5 \%$ SDS-polyacrylamide gels with a low molecular weight marker (GE Healthcare Bioscience). Gels were then stained with silver for further analysis and with Coomassie brilliant blue R-250 for mass spectrometry for protein identification. The silver-stained gels were scanned at a 300 -dpi resolution and protein spots were analyzed with the ImageMaster Platinum ${ }^{\mathrm{TM}}$ software (GE Healthcare Bioscience) according to manufacturer recommendations. For each sample, we performed electrophoresis followed by silver staining three times. Spots with a $\mathrm{P}$ value $\leq 0.05$ for the $t$-test and a 2.0 -fold or greater alteration in abundance were accepted as significantly changed proteins. The differentially expressed protein spots were cut and digested using a method based on a previous study by Jin et al. (21).

\section{Peptide mass fingerprinting by matrix-assisted laser desorption/ionization time-of-flight mass spectrometry (MALDI-TOF-MS)}

An aliquot $(0.5 \mu \mathrm{L})$ of tryptic peptides was mixed with $1.5 \mu \mathrm{L}$ matrix consisting of a saturated solution of alphacyano-4-hydroxycinnamic acid in 50\% (v/v) acetonitrile per $0.1 \%(\mathrm{v} / \mathrm{v})$ trifluoroacetic acid. The mixture $(1 \mu \mathrm{L})$ was immediately added to a MALDI plate and dried at room temperature. The dried spots were analyzed with a Bruker REFLEX III MALDI-TOF-MS (Bruker-Franzen, Germany) in positive ion mode at an accelerating voltage of $20 \mathrm{kV}$. The spectra were internally calibrated using trypsin autolysis products. The peptide mass fingerprints (PMF) were used to search through the SWISS-PROT and NCBInr databases using the Mascot search engine (http:// www.matrixscience.co.uk). The MS peak filtering included the following parameters: a mass range of 800 to $4000 \mathrm{Da}$ with a tolerance of $0.1 \mathrm{Da}$; fixed and variable modifications due to carbamidomethylation (C) and oxidation (M), 
respectively, and a maximum of 1 missed cleavage for trypsin digestion. The results were acceptable as a positive identification when score confidence was higher than $95 \%$.

\section{Peptide sequencing by electrospray ionization nanoelectrospray tandem MS (ESI-MS/MS)}

ESI-MS/MS experiments were conducted using a QTOF 2 hybrid quadrupole TOF mass spectrometer (Micromass, UK) with a nanoflow Z-spray source. Peptide sequencing was performed using a palladiumcoated borosilicate electrospray needle (Protana, Denmark) according to the method of Yan et al. (22). The MS was operated in the positive ion mode with a source temperature at $80^{\circ} \mathrm{C}$, and a potential of 800 to $1000 \mathrm{~V}$ applied to the nanospray probe. The amino acid sequences of the peptides were deduced with the peptide sequencing program MasSeq and the database search was completed with the Mascot search engine using data processed through MaxEnt3 and MasSeq programs.

\section{Real-time quantitative polymerase chain reaction (RT-PCR)}

Splenocytes were isolated as described by Abe et al. (23). RNA from splenocytes was extracted using TRIzol reagents (Invitrogen Corporation, USA) according to manufacturer instructions. Quantification was carried out using absorbance at $260 \mathrm{~nm}$ and quality was confirmed by $1 \%$ agarose gel electrophoresis. RNA samples $(n=3)$ with an $A_{260 \mathrm{~nm}} / A_{280 \mathrm{~nm}}$ of $1.8-2.0$ were stored at $-80^{\circ} \mathrm{C}$ for further analysis.

For the M-T413 gene, the forward and reverse primers were 5'-GAC CCA ATC TCC AGC TTC TTT G-3' and 5' CGT TTT ATT TCC AGC TTG GTC CC-3', respectively; for the $\beta$-actin gene, the forward and reverse primers were 5'-TTG CTG ACA GGA TGC AGA AGG AG-3' and 5'GTG GAC AGT GAG GCC AGG AT-3', respectively. These primers were designed using the Primer Premier 5.0 software and synthesized by Shenggong Corporation (China). Quantitative RT-PCR was carried out with a thermal cycler (Applied Biosystems, USA) by monitoring the amount of fluorescence increase due to the binding of SYBR green to double-stranded DNA. RT-PCR was performed on a final volume of $20 \mu \mathrm{L}$ containing $1 \mu \mathrm{g}$ RNA template, $1.6 \mu \mathrm{L}$ of mixed primers, $400 \mu \mathrm{M}$ of each dNTP, $0.4 \mu \mathrm{L}$ AMV reverse-transcribed enzyme (5 $U / \mu \mathrm{L})$, $4000.4 \mu \mathrm{L}$ Tfl DNA polymerase, $0.2 \mu \mathrm{L}$ SYBR green, and $10 \mu \mathrm{L}$ reaction buffer using an Access RT-PCR System (Promega Corporation, USA). Briefly, the RNA template was reverse-transcribed into cDNA templates for $45 \mathrm{~min}$ at $48^{\circ} \mathrm{C}$ and denatured for $2 \mathrm{~min}$ at $94^{\circ} \mathrm{C}$, and the denatured CDNA templates were amplified by cycles of $94^{\circ} \mathrm{C}$ for $30 \mathrm{~s}, 64^{\circ} \mathrm{C}$ for $60 \mathrm{~s}$, and $72^{\circ} \mathrm{C}$ for $120 \mathrm{~s}$. Thirtyfour cycles were performed to determine the linearity of the PCR amplification, and amplified $\beta$-actin cDNA served as a control for cDNA quality and quantification.
Fluorescence measurements were recorded after each extension step. At the end of each PCR run, data were automatically analyzed by the system and amplification plots were generated. Data were calculated using the standard curve of the gene template, normalized with $\beta$-actin.

\section{Flow cytometry analysis}

$\mathrm{CD}^{+}{ }^{+} \mathrm{T}$ cells in peripheral blood were analyzed with a FACScalibur flow cytometer equipped with the CellQuest software (BD Biosciences, USA). Blood samples $(n=5)$ were incubated with phycoerythrin-conjugated anti-CD4 antibodies (BD Biosciences) and fluorescein isothiocyanate-conjugated anti-CD3 (BD Biosciences) for $30 \mathrm{~min}$ at $4^{\circ} \mathrm{C}$ in the dark. A $0.1-\mathrm{mL}$ blood sample was added to $2 \mathrm{~mL}$ BD FACS Lysing Solution (BD Biosciences) to lyse red blood cells. Following fixation with $1 \%$ formaldehyde, the percentage of $\mathrm{CD}_{4}{ }^{+} \mathrm{T}$ cells was detected. The white blood cell count and lymphocyte size were examined by automatic cytometry. The formula for calculating the $\mathrm{CD}^{+}{ }^{+} \mathrm{T}$ cell count was defined as the white blood cell count $x$ percentage of lymphocyte $x$ percentage of CD4 ${ }^{+}$ $T$ cells.

\section{Statistical analysis}

Data are reported as means \pm SD. The Student paired $t$-test was employed to evaluate the differences in means between the 2 strains and Pearson's correlation analysis was used to identify the relationship between the continuous variables of interest. A comparison was considered to be significant if the two-sided $P$ value was less than 0.05 .

\section{Results}

\section{Comparison of protein expression profiles between sera from SAMP8 and SAMR1 mice}

We first separated serum proteins from SAMP8-2 m, $-6 \mathrm{~m},-12 \mathrm{~m}$, and $-15 \mathrm{~m}$ and age-matched SAMR1 mice by $2-D E$. A total of 315 spots were detected on the maps by silver staining, and the overall protein expression profiles with $\mathrm{pH}$ 3-10 and molecular masses of 10 to $90 \mathrm{kDa}$ were very similar within each predetermined group after analysis by the ImageMaster 2-D Platinum software, indicating the stability and reproducibility of 2-DE in our test system.

Two representative 2-DE gel images from SAMP8 and SAMR1 mice are illustrated in Figure 1, showing that 7 differentially expressed proteins were detected when the two strains were compared. Specifically, spots 1-5 appeared in all SAMP8 mouse serum samples, but only appeared in SAMR1 mouse samples at the age of 15 months, with the exception of spot 3 , which showed a slight expression in SAMR1-12 m mouse sera (Table 1 and Figures 1, 2A and $3 A$ ). In addition, spots 6 and 7 appeared in the sera from SAMP8-2 $m,-6 m$, and $-12 m$, 


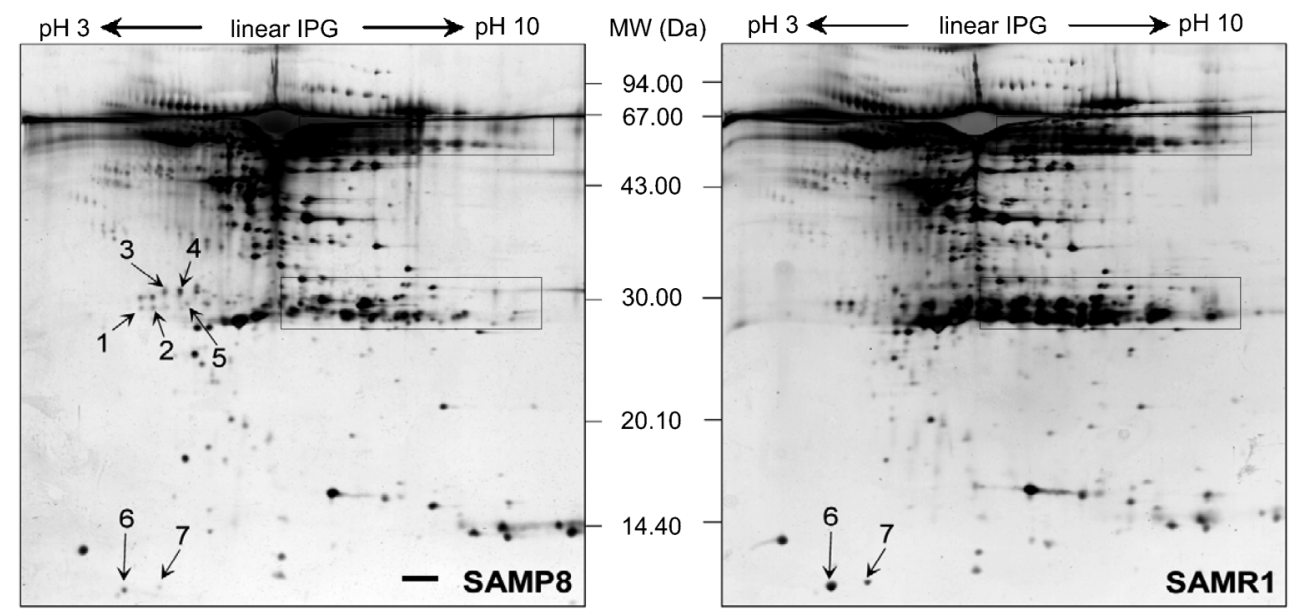

Figure 1. Representative 2-dimensional gels of serum proteins and differentially expressed protein spots. After determining the protein concentration using the Bradford assay, $150 \mu \mathrm{g}$ serum protein was loaded on pH 3-10 linear IPG (Immobilized pH Gradient) strips (18 cm) for the first dimension electrophoresis and were then transferred to vertical $12.5 \%$ SDS-polyacrylamide gel for the second dimension electrophoresis. The gel was visualized by silver staining and analyzed by the ImageMaster Platinum ${ }^{\mathrm{TM}}$ software. The spots with different intensities when SAMP8 was compared to SAMR1 mice (12 months of age) were marked with arrows. The protein spots could not be further analyzed by mass spectrometry since they were not separated into single spots, as marked with rectangles. Bar $=1 \mathrm{~cm}$.

and divided into 2 spots each with mass and charge differing from those of the same spots in SAMP8-15 $\mathrm{m}$ sera (Figure 2B).

\section{Identification of proteins by MALDI-TOF-MS with PMF and ESI-MS/MS with peptide sequences}

After MALDI-TOF-MS and ESI-MS/MS analyses, spots 3 to 6 were identified as Ig kappa chain $V$ region (M-T413), chain A of an activity suppressing Fab fragment to cytochrome P450 aromatase (32C2_A), alpha-fetoprotein, and apolipoprotein A-II (Apo $\bar{A}-\mathrm{II}$ ), respectively. However, because the database search yielded no peptides whose score was high enough to provide unambiguous results and because no qualified peptides could be detected by ESI-MS/MS sequencing, the remaining 3 protein spots unfortunately were not identified in the present study. Information about the 7 aforementioned protein spots is summarized in Table 1.

\section{Expression of M-T413 in SAMP8 splenocytes}

Previous studies have demonstrated that decreased $T$ cell immune function is closely related to age-associated cognitive impairment in SAMP8 mice (23-25). The cause of the decreased T cell immune function in SAMP8 mice remains an open question. In the present study, we identified a differentially expressed protein (M-T413) via joint PMF and peptide sequencing (Figure 3 and Table 1). M-T413 is a monoclonal CD4 antibody binding to the CD4 $\mathrm{V} 1$ domain and can inhibit $\mathrm{T}$ cell proliferation in a mixed lymphocyte response, thus acting to immunosuppress the $\mathrm{CD}^{+} \mathrm{T}$ cell response (26-28). In the present study, MT413 was expressed in all SAMP8 mouse sera and in the sera from SAMR1-12 $\mathrm{m}$ and -15 m mice (Figure 2, Figure $3 A$ and Table 1), exhibiting a close association with senescence. However, since an anti-M-T413 antibody is not commercially available, serum M-T413 protein could not be determined by ELISA or Western blot. However, as an Ig kappa chain $\mathrm{V}$ region, we hypothesized that M-T413 was produced by $B$ lymphocytes mainly derived from the spleen. Therefore, the M-T413 mRNA level was assessed in splenocytes from SAMP8 and age-matched SAMR1 mice. M-T413 mRNA was significantly enhanced in splenocytes from SAMP8-2 m mice (Figure 3B) compared to that from age-matched SAMR1 mice, in agreement with M-T413 protein changes in sera from 2-month old mice (Figure 3A), which once again validated the correlation of M-T413 with early impaired cognition. However, inconsistent with the M-T413 protein existing in SAMR1-12 m mouse sera, we observed that the M-T413 RNA level was elevated in the SAMR1 mouse spleen from 6 months of age, and maintained at a higher level until 15 months of age (Figure 3B). It is likely that splenocytes are not the unique source of serum M-T413, which warrants further evaluation.

\section{$\mathrm{CD}^{+} \mathrm{T}$ cell count in SAMP8 blood}

Furthermore, another report by Abe et al. (23) indicating the decreased number of $\mathrm{CD}^{+}{ }^{+} \mathrm{T}$ cells in the SAMP8-2 $m$ mouse spleen with respect to the agematched SAMR1 mouse spleen, combined with our observation of the elevated M-T413 RNA level, led us to speculate that M-T413 might be accountable for CD4 ${ }^{+} \mathrm{T}$ cell variability. This speculation was further strengthened by the fact that no material changes were observed in the 


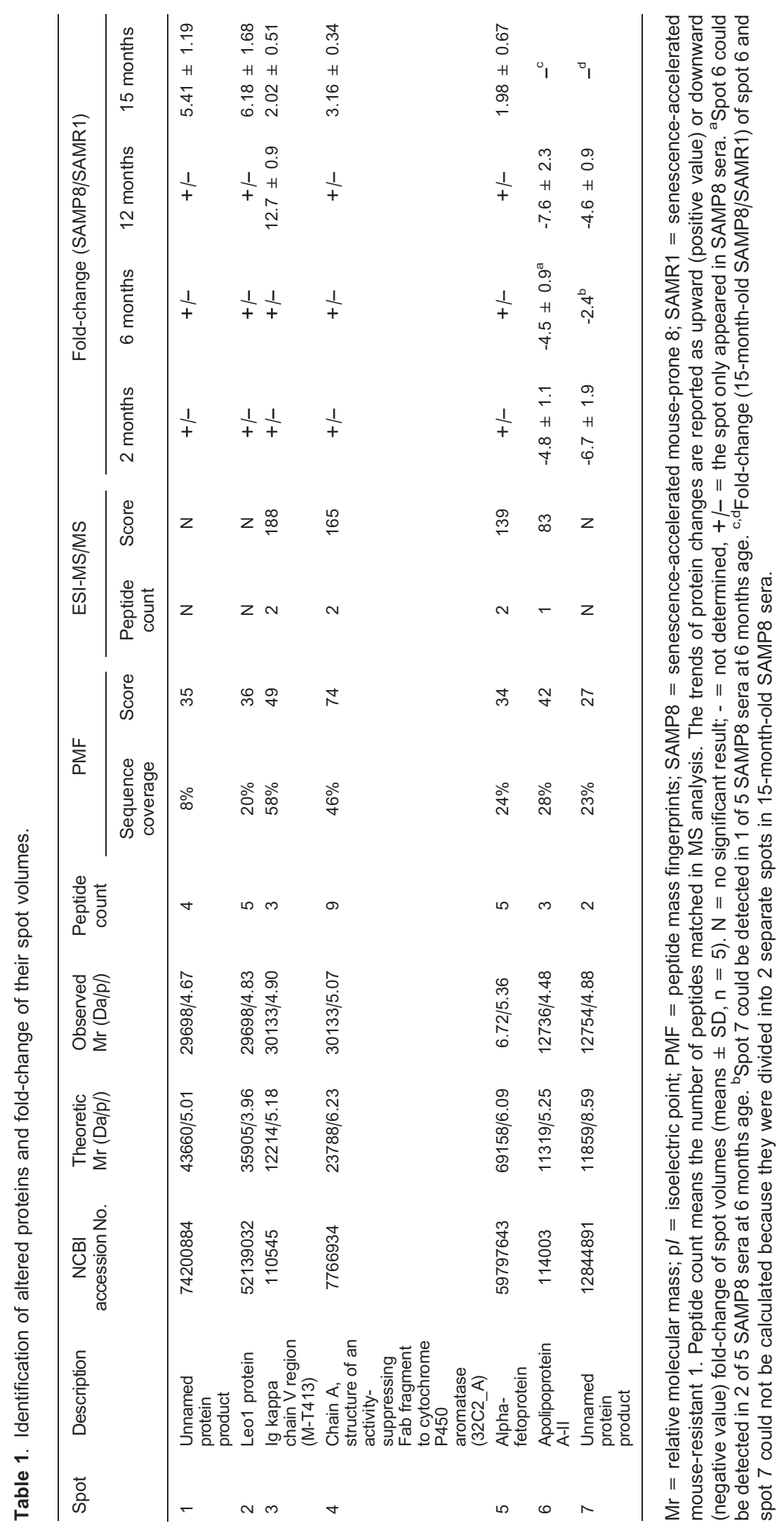



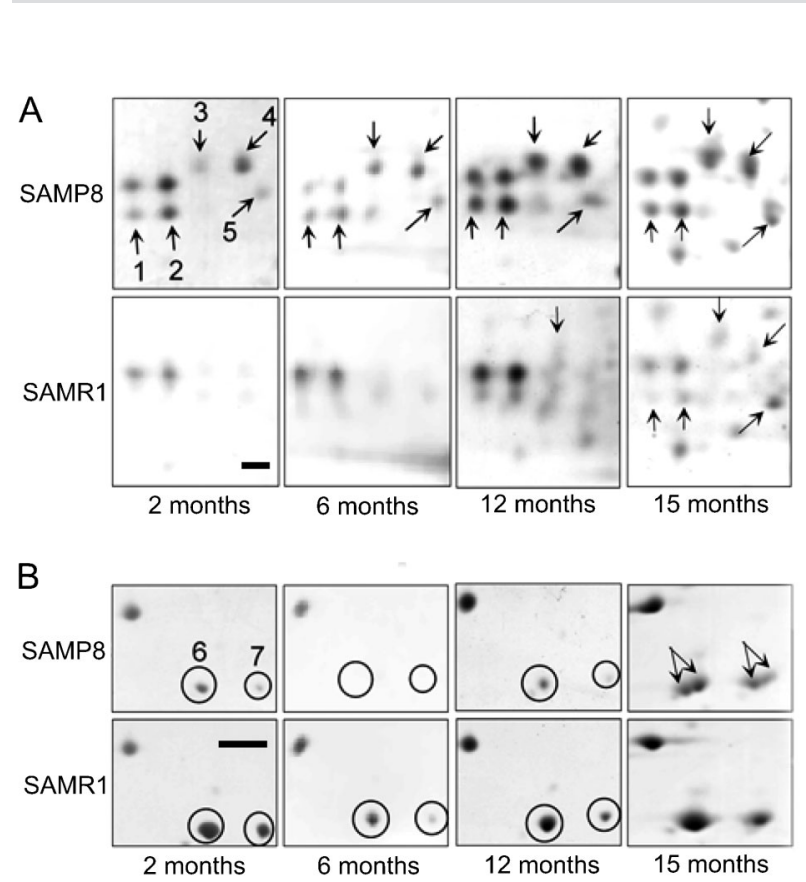

Figure 2. Enlarged 2-DE maps of 7 differentially expressed proteins in sera from mice at 2, 6, 12, and 15 months. $A$, Spots 1 to 5 (marked with arrows) were expressed in all serum samples from SAMP8 mice and in SAMR1-15 m mice, except for a slight expression of spot 3 in SAMR $1-12 \mathrm{~m}$ sera. Bar $=1 \mathrm{~cm}$. $B$, Spots 6 and 7 (marked with circles) were significantly down-regulated in sera from SAMP8-2 $\mathrm{m},-6 \mathrm{~m}$, and $-12 \mathrm{~m}$ mice, and divided into 2 spots in SAMP8-15 m mouse sera (marked with arrows). Bar $=1 \mathrm{~cm}$.

number of $\mathrm{CD}^{+}{ }^{+} \mathrm{T}$ cells in the SAMP8-5 m mouse spleen in the study by Abe et al. (23), or in the M-T413 RNA level observed in the splenocytes of SAMP8 mice at 6 months and onwards in the present study (Figure 3B). To further address this hypothesis, we determined $\mathrm{CD}^{+}{ }^{+} \mathrm{T}$ cell counts in blood samples from both SAMP8 and SAMR1 mice. As shown in Figure $3 \mathrm{C}$, the $\mathrm{CD}^{+}{ }^{+} \mathrm{T}$ cell count in SAMP8 mouse blood was strikingly lower than that in the age-matched SAMR1 mice, which negatively correlated with serum M-T413 protein volume $(r=-0.821, \mathrm{P}=$ 0.013). Taken together, these results support our speculation that M-T413 might be one of the important reasons for reduced $\mathrm{CD}^{+}{ }^{+} \mathrm{T}$ cells in SAMP8 mice.

\section{Discussion}

In clinical practice, the evaluation of imaging findings has been incorporated into the diagnosis of $A D$ along with traditional clinical criteria $(29,30)$. Generally, an ideal biomarker for disease diagnosis should have relatively high sensitivity and specificity, and should have potential advantages for early detection. In view of the difficulties encountered in AD diagnosis, the screening of early stage biomarker candidates from an ideal animal model is highly desirable. Bearing this in mind, we explored the alterations of serum proteins in SAMP8 mice related to age,
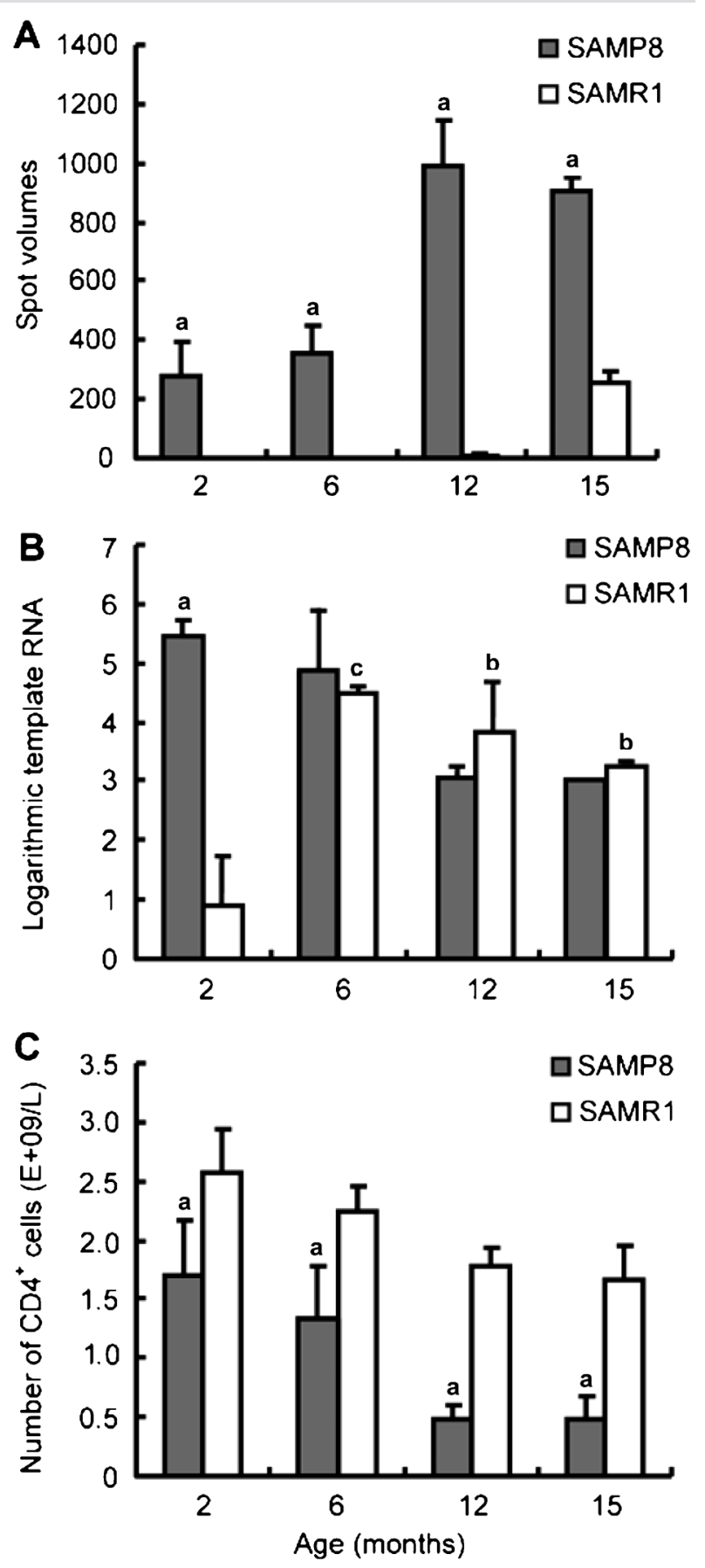

Figure 3. M-T413 expression in sera and splenocytes and CD4 ${ }^{+} \mathrm{T}$ cell count in peripheral blood. $A$, The spot volume of M-T413 was greatly increased in SAMP8 mouse sera compared to SAMR1 mice at all ages. ${ }^{\text {a }} \mathrm{P}<0.01 \mathrm{vs}$ age-matched SAMR1 (Student paired $t$-test). $B$, M-T413 mRNA level was higher in SAMP8 mouse splenocytes than in SAMRI mouse splenocytes at 2 months of age. In SAMR1 mouse splenocytes, mM-T413 RNA was elevated from 6 months of age and maintained at a higher level until 15 months of age. ${ }^{\text {a }} \mathrm{P}<0.01$ vs age-matched SAMR1. ${ }^{\mathrm{b}} \mathrm{P}<0.05,{ }^{\mathrm{c}} \mathrm{P}<0.01$ vs 2 -month-old SAMR1 (Student paired $t$-test). $C$, The $\mathrm{CD}^{+}{ }^{+} \mathrm{T}$ cell count was much lower in SAMP8 mouse blood compared to SAMR1 mice at all ages. aP $<0.01$ vs age-matched SAMR1 (Student paired $t$-test). 
which, as a non-transgenic strain with accelerated senescence, are accepted as a suitable model for assessing the pathophysiological features of AD (31-33).

Specific expression of spots 1 to 5 in SAMP8 and SAMR1 mouse serum at 15 months of age enabled us to conclude that these differential spots might have a close relationship both with accelerated senescence and normal aging.

Unlike the spots mentioned above, spots 6 and 7 did not exhibit changes similar to those that occurred in the normal aging process, suggesting that their alteration was only associated with accelerated senescence. However, spots 1 to 7 showed significant changes as early as by 2 months of age, and thus they might serve as candidate biomarkers of early deficits in cognition. Accordingly, we analyzed these "differential" spots using MALDI-TOF-MS and ESI-MS/MS after tryptic in-gel digestion.

\section{C2_A, alpha-fetoprotein and Apo A-II}

Besides the M-T413 protein mentioned in the Results section, 32C2_A and alpha-fetoprotein were also reported to be involved in senescence among differentially expressed proteins identified for the first time in the present study. In the present study, the expression of 32C2_A (spot 4), an autoantibody suppressing cytochrome P450 aromatase activity (34), was only detected in sera from all SAMP8 mice and SAMR1-15 m mice (Figure 2A). P450 aromatase, as a key enzyme in estrogen biosynthesis, can convert androgen to estrogen (35). We thus speculated that 32C2_A might inhibit estrogen biosynthesis by suppressing the activity of P450 aromatase. This was supported by our previous observation that the concentration of serum estradiol was lower in all SAMP8 mice compared to SAMR1 mice (17). In addition, elevations of M-T413, 32C2_A and anti-elastin antibodies (20) in SAMP8 mouse sera suggest that autoantibodies play a part in the impaired cognition of SAMP8 mice.

We also identified another protein, alpha-fetoprotein (spot 5), in serum samples from all SAMP8 mice and SAMR1-15 $\mathrm{m}$ mice (Figure 2A). Alpha-fetoprotein is a serum alpha-globulin synthesized by embryo hepatocytes and the yolk sac during the embryonic stage and is nearly undetectable in adult serum (36). It serves as a marker for the diagnosis of hepatocellular carcinoma owing to a raised synthesis and secretion when tumors occur (37). In the present study, a very novel finding was alphafetoprotein showed a close correlation with impaired cognition, so that the exact mechanism of its expression in sera of accelerating senescence mice remains worthy of further investigation.

Another protein involved in senile amyloidosis, Apo A-
II (spot 6), was decreased in sera from SAMP8-2 m, -6 m, and $-12 \mathrm{~m}$ mice, and divided into 2 spots in SAMP8-15 m mouse sera as shown in Figure 2B. There are 3 types of Apo A-II: type A Apo A-II, type B Apo A-II, and type C Apo A-II. In these 3 types, amino acid substitutions have been reported at a total of 4 different positions. An Apo A-II with methionine at position 26 was detected in SAMP8, SAMP3, SAMR2, and C57BL/6J mice with a moderate incidence of amyloid deposition; B Apo A-II with proline substituted at position 5 was mainly observed in SAMR1, SAMR4, SAMP6, and BALB/C mice with a low incidence of senile amyloidosis, and C Apo A-Il was found in SAMP1, SAMP2, SAMP7, and SAMP9 mice with a severe and high incidence of amyloidosis (38). In view of this evidence, we conjectured that spot 6 might be B Apo A-II due to its higher abundance in SAMR1 mice, whereas its actual type requires further identification.

The limitations of the present study include 3 of the 7 proteins being unsuccessfully identified and no verification of M-T413 expression changes in SAMP8 mouse serum owing to the unavailability of an M-T413 antibody. Moreover, besides the 7 proteins mentioned above, the count and abundance of protein spots with an isoelectric point $(p /)$ between 5.4-8.3 and relative molecular mass $(\mathrm{Mr})$ of 5.3-6.7, and of protein spots with a $\mathrm{p} /$ between 4.98.0 and $\mathrm{Mr}$ of 2.8-3.2 also differed significantly between the 2 strains (Figure 1). These protein spots could not be further analyzed by MS because they were not separated into single spots.

Despite these limitations, our study still showed that the expression levels of some serum proteins, especially the autoantibodies, were significantly different between SAMP8 and SAMR1 mice from 2 months of age onwards. Our results may provide a reference point for the understanding of the basic pathophysiological mechanisms of learning and memory deficits, and these changed proteins may serve as candidate biomarkers of early impaired cognition. On this basis, future investigations can focus on elucidating the role and mechanisms of these proteins in age-related cognitive impairment and identify additional potential serum biomarkers using further proteomic methods such as narrow $\mathrm{pH}$ range IPG strips and the removal of high abundance serum proteins.

\section{Acknowledgments}

Research supported by grants from the National Natural Science Foundation of China (\#30200367, \#90709012) and the Shanghai Jiaotong University School of Medicine (\#11xj21034).

\section{References}


their therapeutic implications. Annu Rev Pathol 2006; 1: 151-170, doi: 10.1146/annurev.pathol.1.110304.100113.

2. Takeda T. Senescence-accelerated mouse (SAM) with special references to neurodegeneration models, SAMP8 and SAMP10 mice. Neurochem Res 2009; 34: 639-659, doi: 10.1007/s11064-009-9922-y.

3. Chen GH, Wang YJ, Wang XM, Zhou JN. Accelerated senescence prone mouse- 8 shows early onset of deficits in spatial learning and memory in the radial six-arm water maze. Physiol Behav 2004; 82: 883-890.

4. Wei X, Zhang Y, Zhou J. Alzheimer's disease-related gene expression in the brain of senescence accelerated mouse. Neurosci Lett 1999; 268: 139-142, doi: 10.1016/S03043940(99)00396-1.

5. Poon HF, Farr SA, Banks WA, Pierce WM, Klein JB, Morley $\mathrm{JE}$, et al. Proteomic identification of less oxidized brain proteins in aged senescence-accelerated mice following administration of antisense oligonucleotide directed at the Abeta region of amyloid precursor protein. Brain Res Mol Brain Res 2005; 138: 8-16, doi: 10.1016/j.molbrainres.2005.02.020.

6. Kumar VB, Franko MW, Farr SA, Armbrecht HJ, Morley JE. Identification of age-dependent changes in expression of senescence-accelerated mouse (SAMP8) hippocampal proteins by expression array analysis. Biochem Biophys Res Commun 2000; 272: 657-661, doi: 10.1006/bbrc.2000.2719.

7. Butterfield DA, Poon HF. The senescence-accelerated prone mouse (SAMP8): a model of age-related cognitive decline with relevance to alterations of the gene expression and protein abnormalities in Alzheimer's disease. Exp Gerontol 2005; 40: 774-783, doi: 10.1016/j.exger.2005.05.007.

8. Poon HF, Castegna A, Farr SA, Thongboonkerd V, Lynn BC, Banks WA, et al. Quantitative proteomics analysis of specific protein expression and oxidative modification in aged senescence-accelerated-prone 8 mice brain. Neuroscience 2004; 126: 915-926, doi: 10.1016/j.neuroscience.2004.04.046.

9. Díez-Vives C, Gay M, Garcia-Matas S, Comellas F, Carrascal M, Abian J, et al. Proteomic study of neuron and astrocyte cultures from senescence-accelerated mouse SAMP8 reveals degenerative changes. J Neurochem 2009; 111: 945-955, doi: 10.1111/j.1471-4159.2009.06374.x.

10. Cheng XR, Zhou WX, Zhang YX, Zhou DS, Yang RF, Chen LF. Differential gene expression profiles in the hippocampus of senescence-accelerated mouse. Neurobiol Aging 2007; 28: 497-506, doi: 10.1016/j.neurobiolaging.2006.02.004.

11. Cho YM, Bae SH, Choi BK, Cho SY, Song CW, Yoo JK, et al. Differential expression of the liver proteome in senescence accelerated mice. Proteomics 2003; 3: 18831894, doi: 10.1002/pmic.200300562.

12. Liu Y, He J, Ji S, Wang Q, Pu H, Jiang T, et al. Comparative studies of early liver dysfunction in senescence-accelerated mouse using mitochondrial proteomics approaches. Mol Cell Proteomics 2008; 7: 1737-1747, doi: 10.1074/ mcp.M800109-MCP200.

13. Nabeshi H, Oikawa S, Inoue S, Nishino K, Kawanishi S. Proteomic analysis for protein carbonyl as an indicator of oxidative damage in senescence-accelerated mice. Free Radic Res 2006; 40: 1173-1181, doi: 10.1080/ 10715760600847580.

14. Zhu L, Yu J, Shi Q, Lu W, Liu B, Xu S, et al. Strain- and age- related alteration of proteins in the brain of SAMP8 and SAMR1 mice. J Alzheimers Dis 2011; 23: 641-654.

15. Luo Y, Li Y, Lin C, Ma H, Zhang J, Wu S, et al. Comparative proteome analysis of splenic lymphocytes in senescenceaccelerated mice. Gerontology 2009; 55: 559-569, doi: 10.1159/000225958.

16. Flood JF, Farr SA, Kaiser FE, La Regina M, Morley JE. Agerelated decrease of plasma testosterone in SAMP8 mice: replacement improves age-related impairment of learning and memory. Physiol Behav 1995; 57: 669-673, doi: 10.1016/0031-9384(94)00318-1.

17. Ma $Y$, Zhou $W X$, Cheng JP, Zhang YX. Age-related changes in the oestrous cycle and reproductive hormones in senescence-accelerated mouse. Reprod Fertil Dev 2005; 7: $507-512$.

18. Jiang N, Yan X, Zhou W, Zhang Q, Chen H, Zhang Y, et al. NMR-based metabonomic investigations into the metabolic profile of the senescence-accelerated mouse. J Proteome Res 2008; 7: 3678-3686, doi: 10.1021/pr800439b.

19. Oaki K, Asano K, Okamoto K, Yoshida T, Kuroiwa Y. Changes of IgE production in senescence-accelerated mice SAMP8. In Vivo 1996; 10: 417-420.

20. Atanasova M, Konova E, Georgieva M, Dimitrova A, Coquand-Gandit M, Faury G, et al. Age-related changes of anti-elastin antibodies in senescence-accelerated mice. Gerontology 2010; 56: 310-318, doi: 10.1159/000238304.

21. Jin BF, He K, Wang HX, Wang J, Zhou T, Lan Y, et al. Proteomic analysis of ubiquitin-proteasome effects: insight into the function of eukaryotic initiation factor $5 \mathrm{~A}$. Oncogene 2003; 22: 4819-4830, doi: 10.1038/sj.onc.1206738.

22. Yan JX, Wait R, Berkelman T, Harry RA, Westbrook JA, Wheeler $\mathrm{CH}$, et al. A modified silver staining protocol for visualization of proteins compatible with matrix-assisted laser desorption/ionization and electrospray ionization-mass spectrometry. Electrophoresis 2000; 21: 3666-3672, doi: 10.1002/1522-2683(200011)21:17<3666::AIDELPS3666>3.0.CO;2-6.

23. Abe $Y$, Yuasa M, Kajiwara $Y$, Hosono M. Defects of immune cells in the senescence-accelerated mouse: a model for learning and memory deficits in the aged. Cell Immunol 1994; 157: 59-69, doi: 10.1006/cimm.1994.1205.

24. Zhang $\mathrm{Y}$, Moriguchi $\mathrm{T}$, Saito $\mathrm{H}$, Nishiyama N. Functional relationship between age-related immunodeficiency and learning deterioration. Eur J Neurosci 1998; 10: 38693875, doi: 10.1046/j.1460-9568.1998.00393.x.

25. Oomura Y, Sasaki K, Li A, Yoshii H, Fukata Y, Yago H, et al. Protection against impairment of memory and immunoreactivity in senescence-accelerated mice by acidic fibroblast growth factor. Ann N Y Acad Sci 1996; 786: 337-347, doi: 10.1111/j.1749-6632.1996.tb39075.x.

26. Weissenhorn W, Chen YH, Reiter C, Federle C, Weiss EH, Riethmuller G, et al. Structural diversity of monoclonal CD4 antibodies and their capacity to block the HIV gp120/CD4 interaction. Hybridoma 1996; 15: 117-124, doi: 10.1089/ hyb.1996.15.117.

27. Looney JE, Willinger A, Lin G, Rieber EP, Riethmuller G, Ghrayeb J. Expression and characterization of cM-T413, a chimeric anti-CD4 antibody with in vitro immunosuppressive activity. J Immunother Emphasis Tumor Immunol 1994; 16: 36-46, doi: 10.1097/00002371-199407000-00004.

28. Rieber EP, Federle C, Reiter C, Krauss S, Gurtler L, Eberle 
J, et al. The monoclonal CD4 antibody M-T413 inhibits cellular infection with human immunodeficiency virus after viral attachment to the cell membrane: an approach to postexposure prophylaxis. Proc Natl Acad Sci U S A 1992; 89: 10792-10796, doi: 10.1073/pnas.89.22.10792.

29. McKhann G, Drachman D, Folstein M, Katzman R, Price D, Stadlan EM. Clinical diagnosis of Alzheimer's disease: report of the NINCDS-ADRDA Work Group under the auspices of Department of Health and Human Services Task Force on Alzheimer's Disease. Neurology 1984; 34: 939-944, doi: 10.1212/WNL.34.7.939.

30. Dubois B, Feldman HH, Jacova C, Dekosky ST, BarbergerGateau P, Cummings J, et al. Research criteria for the diagnosis of Alzheimer's disease: revising the NINCDSADRDA criteria. Lancet Neurol 2007; 6: 734-746, doi: 10.1016/S1474-4422(07)70178-3.

31. Flood JF, Morley JE. Learning and memory in the SAMP8 mouse. Neurosci Biobehav Rev 1998; 22: 1-20, doi: 10.1016/S0149-7634(96)00063-2.

32. Miyamoto M, Kiyota Y, Yamazaki N, Nagaoka A, Matsuo T, Nagawa $Y$, et al. Age-related changes in learning and memory in the senescence-accelerated mouse (SAM). Physiol Behav 1986; 38: 399-406, doi: 10.1016/00319384(86)90112-5.

33. Nishiyama $\mathrm{N}$, Moriguichi $\mathrm{T}$, Zhang $\mathrm{Y}$, Saito $\mathrm{H}$.
Comprehensive studies on learning disability in senescence accelerated mouse prone 8. In: Takeda T (Editor), The SAM model of senescence. Amsterdam: Elsevier; 1994. p 385388.

34. Sawicki MW, Ng PC, Burkhart BM, Pletnev VZ, Higashiyama T, Osawa $Y$, et al. Structure of an activity suppressing Fab fragment to cytochrome P450 aromatase: insights into the antibody-antigen interactions. Mol Immunol 1999; 36: 423-432, doi: 10.1016/S0161-5890(99)00062-0.

35. Means GD, Mahendroo MS, Corbin CJ, Mathis JM, Powell FE, Mendelson CR, et al. Structural analysis of the gene encoding human aromatase cytochrome P-450, the enzyme responsible for estrogen biosynthesis. J Biol Chem 1989; 264: 19385-19391.

36. Gitlin D, Boesman M. Sites of serum alpha-fetoprotein synthesis in the human and in the rat. J Clin Invest 1967; 46: 1010-1016, doi: 10.1172/JCl105590.

37. Abelev Gl. Alpha-fetoprotein as a marker of embryo-specific differentiations in normal and tumor tissues. Transplant Rev 1974; 20: 3-37.

38. Higuchi K, Kitagawa K, Naiki H, Hanada K, Hosokawa M, Takeda T. Polymorphism of apolipoprotein A-II (apoA-II) among inbred strains of mice. Relationship between the molecular type of apoA-II and mouse senile amyloidosis. Biochem J 1991; 279 (Part 2): 427-433. 